\title{
The short- and long-term outcomes of pancreaticoduodenectomy for distal cholangiocarcinoma
}

\author{
Pavel Skalickya , Ondrej Urban ${ }^{b}$, Jiri Ehrmannc, Hana Svebisovad ${ }^{\mathrm{d}}$ Dusan Klose, Jana Tesarikova ${ }^{\mathrm{a}}$, Cestmir Neorale, \\ Katerina Knapkova ${ }^{e}$, Martin Lovecek ${ }^{\mathrm{a}}$
}

Background. The aim of the study was to calculate the short-term and long-term outcomes of curative-intent surgery in distal cholangiocarcinoma (DCC) patients to identify potential prognostic factors.

Patients and Methods. A retrospective cohort study of 32 consecutive DCC patients treated with pancreaticoduodenectomy between 2009-2017. The clinicopathological and histopathological data were evaluated for prognostic factors using the univariable Cox regression analysis. The Overall Survival (OS) was estimated using the Kaplan-Meier analysis. Results. The study comprised a total of 32 patients, with a mean age of $65.8( \pm 9.0)$ years at the time of surgery. R0 resection was achieved in $25(86.2 \%)$ patients, 19 (65.5\%) patients received adjuvant oncological therapy. The OS rates at 1,3 and 5 years were $62.5 \%, 37.5 \%$ and $21.9 \%$, respectively. The 90 -day mortality was $3 / 32$ (9.4\%) accounting for one-fourth of the first-year mortality rate. The median OS was 28.5 months. The only statistically significant prognostic factor was vascular resection, which was associated with worse OS in the univariable analysis (HR: 3.644; 95\%-Cl: 1.179-11.216, $P=0.025$ ). An age less than 65 years, ASA grade I/II, hospital stay of fewer than 15 days, R0 resection, lymph node ratio less than 0.2 and adjuvant oncological therapy tended to be associated with better OS but without statistically significant relevance.

Conclusion. The main factor directly influencing the survival of DCC patients is surgical complications. Surgical mortality comprises a significant group of patients, who die in the first year following pancreaticoduodenectomy. Vascular resection is the most important negative prognostic factor for long-term survival.

Key words: cholangiocarcinoma, pancreaticoduodenectomy, long-term survival, prognostic factor

Received: January 18, 2021; Revised: April 12, 2021; Accepted: June 24, 2021; Available online: August 10, 2021

https://doi.org/10.5507/bp.2021.043

(c) 2022 The Authors; https://creativecommons.org/licenses/by/4.0/

${ }^{a}$ Department of Surgery I, University Hospital Olomouc, Czech Republic

${ }^{b}$ Department of Internal Medicine II - Gastroenterology and Geriatrics, Faculty of Medicine and Dentistry, Palacky University Olomouc, Czech Republic

'Department of Clinical and Molecular Pathology, Faculty of Medicine and Dentistry, Palacky University Olomouc, Czech Republic

${ }^{d}$ Department of Oncology, University Hospital Olomouc, Czech Republic

eDepartment of Surgery I, Faculty of Medicine and Dentistry, Palacky University Olomouc, Czech Republic

Corresponding author: Martin Lovecek, e-mail:mlovecek@seznam.cz

\section{INTRODUCTION}

Distal cholangiocarcinoma (DCC) is a malignant disease which arises from the bile duct epithelium located in the distal part between the confluence of the cystic duct and above the Ampula of Vater and represents about $20-30 \%$ of all cholangiocarcinomas ${ }^{1-3}$. The incidence is 1.3 to 3.4 cases per 100,000 in Western countries ${ }^{1}$. According to the National Oncological Registry, the incidence is 3.9 cases per 100,000 and the mortality is 3 cases per 100,000 in the Czech Republic ${ }^{4}$. While the incidence and mortality have been decreasing slightly during the last 10 years, the DCC prognosis remains dismal and the total 5-year survival is $3.6-4.1 \%$ (ref. $\left.{ }^{5}\right)$. In a group of patients treated by curatively intended surgery, the OS is significantly higher with a 5-year survival rate of $18-54 \%\left(\right.$ ref. $\left.^{6,7}\right)$.

Symptoms of DCC include obstructive jaundice with/ without weight loss $^{8}$. The only potentially curative treatment modality is curatively intended surgery - pancreaticoduodenectomy (PD) with removal of the distal part of the bile duct and lymphadenectomy. Among cholangiocarcinomas, DCCs have the highest resectability rate. A specific feature of cholangiocarcinoma is submucosal and perineural spreading of tumour cells along the bile duct. The achievement of real negative resection margins seems very difficult in these cases and macroscopic margins do not correlate with microscopic histopathological spread ${ }^{9}$. R0 status (tumour-free resection margins) is the main goal of the procedure and the most important prognostic factors described previously in the literature are tumour-free resection margins and negative lymph node status ${ }^{2,3}$. In cases of venous infiltration, en bloc resection with portal vein resection might be necessary. There are some specific complications associated with this procedure, which modify the short-term outcome. Other previously described potential prognostic factors are: perineural invasion, venous invasion and postoperative complications ${ }^{1}$.

Most published data analyse inhomogeneous patient groups according to the primary location of the biliary 
tract carcinoma and type of surgical treatment ${ }^{6,8,10,11}$. The aim of this study was to calculate the short-term and longterm treatment outcomes of curative intent surgery in DCC patients and to identify potential prognostic factors.

\section{MATERIALS AND METHODS}

This is a retrospective cohort study using a single-centre database consisting in 32 consecutive DCC patients operated on with curative intent between 2009-2017. All the data were collected prospectively including sex, age, time of surgery, ASA, Intensive Care Unit (ICU) length of stay, hospital stay, in-hospital mortality, 30-day mortality, 90-day mortality, vascular resection and complications classified according to the Clavien-Dindo (CD) classification ${ }^{12}$. Pathological evaluation included radicality (resection margins), grading (low/moderate/high differentiation), T-stage, N-stage (lymph node status), number of lymph node metastases, number of lymph nodes removed, lymph node ratio (LNR), perineural invasion, vascular invasion and lymphatic invasion.

The surgical mortality (in-hospital mortality, 30-day, 90-day) was defined as the death of the patients during primary hospitalisation or during the first 30 and 90 days after the primary surgery.

Specific complications of pancreatic surgery, such as postoperative pancreatic fistula (POPF), delayed gastric emptying (DGE) and postpancreatectomy haemorrhage $(\mathrm{PPH})$ are graded in accordance with the International Study Group of Pancreatic Surgery (ISGPS) definitions ${ }^{13-15}$.

For histopathological evaluation, all the specimens were classified in accordance with the WHO classification of tumours of the digestive system and the results were verified by two independent pathologists. The TNM clinical classification (UICC $7^{\text {th }}$ edition) was used for staging. The definition for $\mathrm{R} 0$ resection was $\geq 1 \mathrm{~mm}$ from the microscopic border of the tumour. An LNR cutoff of 0.20 was used. The impact of these parameters on the OS was evaluated. The OS was measured as the period between the date of surgery and the date of death.

The following criteria were used to assess the resectability of DCC: 1) absence of nodal metastases in the retropancreatic and paraceliac area or distant liver metastases, 2) absence of disseminated disease. PD with removal of the distal part of the bile duct en block with the head of the pancreas, gallbladder, duodenum and standard lymphadenectomy according to the International Study Group for Pancreatic Surgery recommendation (ISGPS) was the standard procedure ${ }^{16}$. The reconstruction was performed with a pancreatojejunostomy, hepaticojejunostomy and duodenojejunostomy performed on the same jejunal loop. In cases of a very soft pancreas with a tiny pancreatic duct, total pancreaticoduodenectomy was an option. Postoperative follow-up was performed every 3 months for two years and then every 6 months for up to five years postoperatively. The follow-up included clinical examination, level of carbohydrate antigen 19-9 (CA 199), abdominal computed tomography every 6 months or in cases of elevated CA 19-9.
For categorical values, absolute numbers and the distribution in percentages on available data are presented. The values of continuous variables are given as median and minimum-maximum range. Differences in survival were analysed from a cohort which excluded patients who died in the first 3 months following surgery, using a univariable Cox proportional hazards regression model. The hazard ratios (HRs) are presented with $95 \%$ confidence intervals (CI). The Kaplan-Meier analysis was used to estimate long-term survival. Statistical analysis was performed with IBM SPSS Statistics version 22.

This study was approved by the Ethics committee of the Faculty Hospital Olomouc.

\section{RESULTS}

\section{Therapy outcomes}

The study comprised a total of 32 patients, $26(81.3 \%)$ men and $6(18.7 \%)$ women, the age of the patients was between 36 and 76 years, with a mean of $65.8( \pm 9.0)$ years at the time of surgery. The patients were mostly scored with a preoperative ASA score II ( $n=25 / 32 ; 78.1 \%)$, a few patients had ASA I $(n=3 / 32 ; 9.4 \%)$ and ASA III $(n=4 / 32$; $12.5 \%$ ), respectively (Table 1 ).

The most common postoperative complications were POPF, wound infection and pneumonia. According to the CD classification, 7 (21.9\%) patients had a grade 0,1 (3.1\%) had a grade I, 14 (43.8\%) grade II, 1 (3.1\%) grade IIIa, 4 (12.5\%) grade IIIb and $2(6.3 \%)$ grade IVb complication. The median total hospital stay was 15 (11-83) days, the ICU stay was 5 (1-77) days. Three patients had to be rehospitalised due to complications. The 90-day mortality was $9.4 \%$ ( $n=3 / 32$ patients). The OS rates at 1,3 and 5 years were $62.5 \%, 37.5 \%$ and $21.9 \%$, respectively (Fig. 1). The median survival was 28.5 months.

\section{Prognostic factor evaluation}

Clinically relevant factors such as sex, age and ASA status do not statistically associate with the OS of DCC patients in our study.

When staged in accordance with UICC $7^{\text {th }}$ edition, 2 patients $(6.9 \%)$ were stage I, $4(13.8 \%)$ were stage IIa, $16(55.2 \%)$ were stage IIb and 7 (24.1\%) were stage III. The histopathological examination revealed lymph node involvement ( $\mathrm{pN} 1)$ in 15 patients $(51.7 \%)$. The majority of the tumours were classified as low and moderately differentiated (grades 1 and 2) in 14 (48.3\%) and in 10 (34.5\%) cases, respectively (Table 2 ). None of these tumour histopathological characteristics was statistically significant as prognostic factors influencing the long-term therapy outcomes (Table 3 ).

$\mathrm{R} 0$ resection was achieved in $25(86.2 \%)$ patients, 19 (65.5\%) patients received adjuvant oncological therapy. Vascular resection was found to be significantly associated with worse OS in the univariable analysis (HR: 3.644; 95\%-CI: $1.179-11.216, P=0.025)$ and the Kaplan-Meier analysis $(P=0.016)$ (Fig. 2).

Concerning the surgery complications, none of them were statistically significantly verified as a prognostic 
Table 1. Clinicopathological and perioperative data for patients with distal adenocarcinoma.

\begin{tabular}{|c|c|}
\hline Variables & $\begin{array}{cc}\mathrm{n}=32 & \mathrm{n}(\%), \\
& \text { median }(\min -\max )\end{array}$ \\
\hline Age (years) & $67(36-76)$ \\
\hline Male sex & $26(81.3 \%)$ \\
\hline \multicolumn{2}{|c|}{ Preoperative biliary drainage } \\
\hline ERCP & $28(87.5 \%)$ \\
\hline PTC & $4(12.5 \%)$ \\
\hline \multicolumn{2}{|l|}{ ASA } \\
\hline Score I & $3(9.4 \%)$ \\
\hline Score II & $25(78.1 \%)$ \\
\hline Score III & $4(12.5 \%)$ \\
\hline Operative time ( $\mathrm{min})$ & $291(194-430)$ \\
\hline Vascular resection & $5(15.6 \%)$ \\
\hline Hospital stay (days) & $15(11-83)$ \\
\hline ICU stay (days) & $5(1-77)$ \\
\hline Rehospitalisation & $3(9.4 \%)$ \\
\hline \multicolumn{2}{|l|}{ Mortality } \\
\hline In-hospital & $2(6.3 \%)$ \\
\hline 30-day & $1(3.1 \%)$ \\
\hline 90-day & $3(9.4 \%)$ \\
\hline \multicolumn{2}{|l|}{ POPF } \\
\hline Grade B & $3(9.4 \%)$ \\
\hline Grade $\mathrm{C}$ & $3(9.4 \%)$ \\
\hline \multicolumn{2}{|l|}{ DGE } \\
\hline Grade A & $0(0.0 \%)$ \\
\hline Grade B & $2(6.3 \%)$ \\
\hline Grade C & $1(3.1 \%)$ \\
\hline \multicolumn{2}{|l|}{$\mathrm{PPH}$} \\
\hline Grade A & $0(0.0 \%)$ \\
\hline Grade B & $2(6.3 \%)$ \\
\hline Grade $\mathrm{C}$ & $3(9.4 \%)$ \\
\hline Wound infection & $7(21.9 \%)$ \\
\hline Pneumonia & $6(18.8 \%)$ \\
\hline \multicolumn{2}{|l|}{ Clavien-Dindo } \\
\hline Grade 0 & $7(21.9 \%)$ \\
\hline Grade I & $1(3.1 \%)$ \\
\hline Grade II & $14(43.8 \%)$ \\
\hline Grade IIIa & $1(3.1 \%)$ \\
\hline Grade IIIb & $4(12.5 \%)$ \\
\hline Grade Iva & $0(0.0 \%)$ \\
\hline Grade IVb & $2(6.3 \%)$ \\
\hline
\end{tabular}

$\mathrm{n}$ number of non-missing values. Qualitative data are expressed as n (\%) and quantitative data as median ( $\min -\max$ )

ASA, American Society of Anesthesiologists; DGE, Delayed gastric emptying; ERCP, Endoscopic retrograde cholangiopancreatography; ICU, Intensive Care Unit; POPF, Postoperative pancreatic fistula; PPH, Postoperative pancreatic haemorrhage; PTC, Percutaneous transhepatic cholangiography.

factor in this study. However, the 90-day mortality was $9.4 \%(n=3 / 32)$ and accounts for one-fourth of the firstyear mortality rate. It was caused only by specific surgical complications - POPF, PPH.

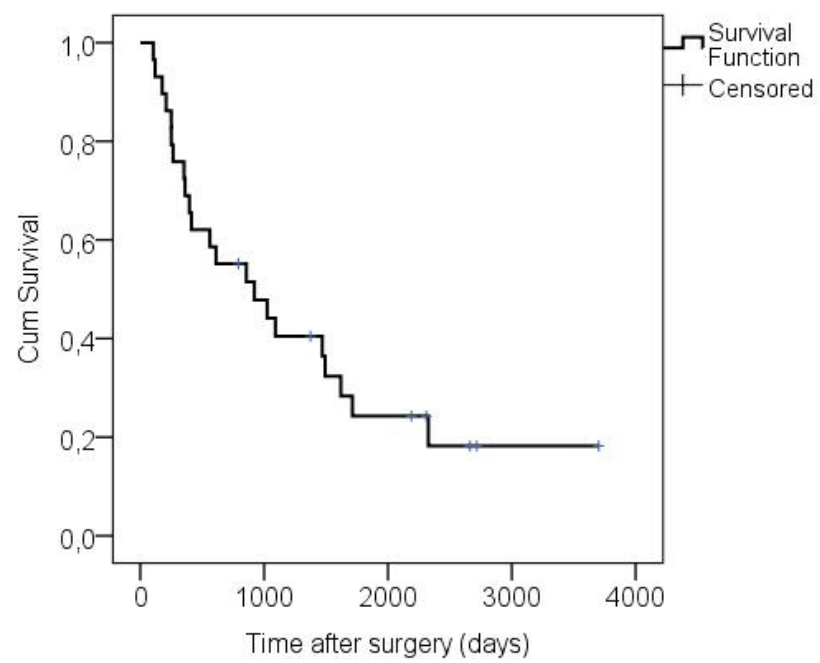

Fig. 1. Overall survival of all patients after resection for distal cholangiocarcinoma estimated using the Kaplan-Meier analysis.

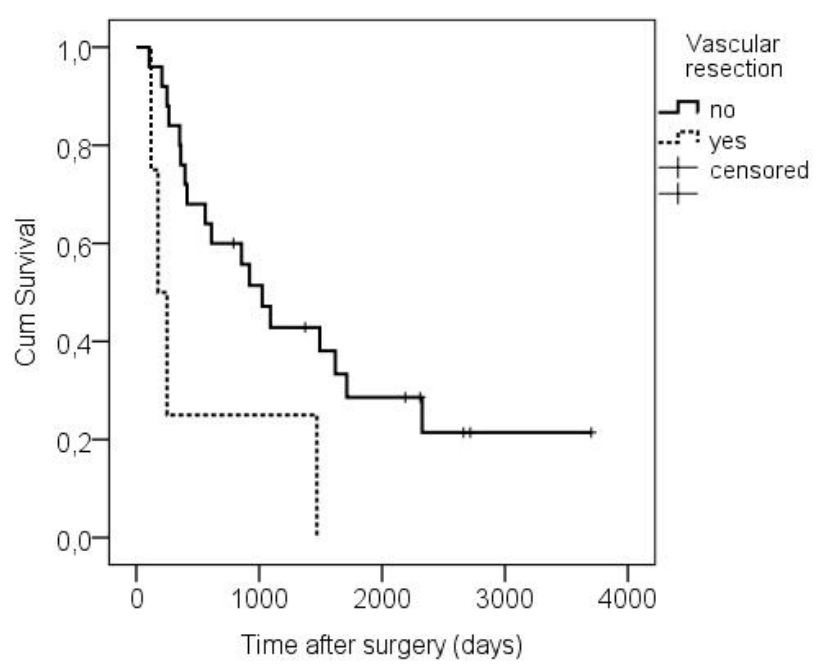

Fig. 2. Overall survival stratified by performing of vascular resection estimated using the Kaplan-Meier analysis $(P=0.016)$.

\section{DISCUSSION}

Cholangiocarcinoma belongs to a group of aggressive cancers of pancreatobiliary origin with a dismal prognosis. Radical surgical resection of PD with lymphadenectomy is the standard therapy for early stage DCC and the only potentially curative therapy to date. In the present study, the median survival was 28.5 months and the 5-year survival was $21.9 \%$. These results are comparable to data recently published by Zhou et al. in a systematic review of DCC survival, where 5-year survival ranged from 13-54\% $\left(\right.$ ref. $\left.^{2}\right)$. The reasons for this wide range in 5-year survival are unclear and variances in genetic factors, risk factors for DCC and patients' selection criteria for surgical treatment may play a crucial role, especially when confronting Asian ${ }^{17-19}$ and European ${ }^{20-24}$ studies.

The previously published prognostic factors for DCC patients who underwent primary surgical treatment were 
Table 2. Histopathological data for patients with distal adenocarcinoma and long-term survival.

\begin{tabular}{|c|c|c|}
\hline Variables & $\mathrm{n}=29$ & $\begin{array}{c}\mathrm{n}(\%), \text { median } \\
(\text { min-max })\end{array}$ \\
\hline \multicolumn{3}{|l|}{ T-stage } \\
\hline Stage 1 & & $2(6.9 \%)$ \\
\hline Stage 2 & & $5(17.2 \%)$ \\
\hline Stage 3 & & $21(72.4 \%)$ \\
\hline Stage 4 & & $1(3.5 \%)$ \\
\hline N1 stage & & $15(51.7 \%)$ \\
\hline $\begin{array}{l}\text { Number of lymph node } \\
\text { metastases }\end{array}$ & & $1(0-5)$ \\
\hline $\begin{array}{l}\text { Number of lymph nodes } \\
\text { removed }\end{array}$ & & $7(1-17)$ \\
\hline $\mathrm{LNR}>0.20$ & & $10(34.5 \%)$ \\
\hline \multicolumn{3}{|l|}{ Grading } \\
\hline G1 & & $5(17.2 \%)$ \\
\hline $\mathrm{G} 2$ & & $10(34.4 \%)$ \\
\hline G3 & & $14(48.8 \%)$ \\
\hline R0 resection & & $25(86.2 \%)$ \\
\hline \multicolumn{3}{|l|}{ UICC stage } \\
\hline Stage I & & $2(6.9 \%)$ \\
\hline Stage IIa & & $4(13.8 \%)$ \\
\hline Stage IIb & & $16(55.2 \%)$ \\
\hline Stage III & & $7(24.1 \%)$ \\
\hline Perineural invasion & & $19(65.5 \%)$ \\
\hline Vascular invasion & & $2(6.9 \%)$ \\
\hline Lymphatic invasion & & $9(31.0 \%)$ \\
\hline
\end{tabular}

$\mathrm{n}$ number of non-missing values. Qualitative data are expressed as $\mathrm{n}$ (\%) and quantitative data as median (min-max).

LNR, lymph node ratio; N1 stage, positive lymph node status; R0resection, radical resection with $\geq 1 \mathrm{~mm}$ from microscopic border of the tumour.

pancreatic and duodenal invasion ${ }^{25}$, surgical margin positivity $^{26,27}$, grades of tumour differentiation ${ }^{23}$, depth of tumour invasion ${ }^{28}$, vascular invasion ${ }^{22,29}$, lymph node metastasis ${ }^{18,27,30}$, perineural invasion ${ }^{31,32}$ and postoperative adjuvant chemotherapy ${ }^{33,34}$. Only perineural invasion, lymph node metastasis, positive resection margin status and not-well-differentiated adenocarcinoma were associated with shorter survival in a large meta-analysis of the above-mentioned studies ${ }^{35}$.
Concerning the tumour-related prognostic factors, we did not verify a statistically relevant association in our study, even though the R0 resection, three or fewer positive lymph nodes, LNR less than 0.2 and adjuvant oncological therapy tended to be associated with better OS but without statistically significant relevance. In our study, an $\mathrm{R} 0$ resection was achieved in $86.2 \%$ of the patients. The results of the OS show some tendency towards a worse OS for an R1 resection (HR: 2.205; 95\%-CI: 0.723-6.724, $P=0.165$ ), but without statistical significance. Similar results have been published in some previous series with an $\mathrm{R} 0$ rate higher than $85 \%$ (ref. ${ }^{1,25}$ ). Other studies with a lower proportion of $\mathrm{R} 0$ resections confirmed $\mathrm{R} 1$ resections as a significant negative prognostic factor on the OS (ref. ${ }^{35,36}$ ) and meta-analysis showed a significant difference in the 5-year survival between those positive and negative for margin status. Therefore the primary endpoint of surgical resection should be an $\mathrm{R} 0$ resection. Preoperative cholangioscopy ${ }^{37}$, frozen section examination of the resection line ${ }^{38}$ and intraoperative cholangioscopy ${ }^{39}$ are helpful in reaching this goal.

Various scale systems are used for the stratification of patients and their prognosis according to lymph node metastasis - lymph node status (N0/N1), number of lymph node metastases, number of lymph nodes removed and LNR (ref. ${ }^{2,17,18,36,40-43}$ ). We did not confirm lymph node status as a statistically significant risk factor for poor survival, contrary to some previous studies ${ }^{17,18,41,43}$. The newest TNM classification ( $8^{\text {th }}$ edition) for DCC is setting up N2 status for patients with more than 4 positive lymph nodes. When comparing patients with 0 to 3 lymph node metastases and 4 lymph node metastases, we found an HR of 2.072 (95\%-CI: $0.820-5.233, P=0.123$ ) for this new $\mathrm{N} 2$ status. This tendency correlates with the results from Kiriyama et al. ${ }^{18}$ and Beetz et al. ${ }^{1}$ LNR can be used as a prognostic tool for gastric, colorectal and pancreatic ductal adenocarcinoma (PDAC) patients ${ }^{44-47}$. Several studies suggested LNR can be a prognostic factor for the survival of patients with DCC (ref. ${ }^{48,49}$ ). From our results' point of view, an LNR with a cutoff of 0.20 has indicated the best correlation with the OS among analysed lymph node parameters with an HR of 2.282 (95\%-CI: 0.932-5.586, $P=0.071$ ) for an LNR greater than 0.20 . The LNR results are on the bounds of statistical significance.

Table 3. Univariable analysis of clinicopathological and histopathological risk factors on overall survival of patients after resection for distal adenocarcinoma.

\begin{tabular}{lccc}
\hline Variables & Hazard ratio & $95 \%$ CI & $P$ \\
\hline ASA score III & 2.134 & $0.700-6.505$ & 0.183 \\
Hospital stay $\geq 15$ days & 0.537 & $0.222-1.301$ & 0.169 \\
R1 resection & 2.205 & $0.723-6.724$ & 0.165 \\
Lymph node metastases $\geq 4$ & 2.072 & $0.820-5.233$ & 0.123 \\
LNR $>0.20$ & 2.282 & $0.932-5.586$ & 0.071 \\
Adjuvant therapy & 0.515 & $0.211-1.257$ & 0.145 \\
\hline
\end{tabular}

The differences in overall survival were analysed using a univariable Cox-regression model

ASA, American Society of Anesthesiologists; LNR, lymph node ratio; R1-resection, nonradical resection with $<1 \mathrm{~mm}$ from microscopic border of the tumour. 
Interestingly, the univariate analysis revealed a statistical significance of surgery-related prognostic factors such as vein resection, which had a statistically significant impact on the long-term survival and surgical complications on the short-term survival in the Kaplan-Meier analysis. This is in concordance with some previous studies, which described a worse prognosis for patients after portal vein resection $^{36,50,51}$, while other studies did not find statistically significant results ${ }^{1,52}$. A limitation for the evaluation of additional vein resection is the small number of patients who could be included, which in our study was only $15.6 \%$ of all patients. The benefit of portal vein resection therefore remains unclear and there is a need for an evaluation by large meta-analysis concerning all these potential factors, in particular the surgical complications.

One year of survival of the whole cohort is $62.5 \%$. Surgical mortality is $9.4 \%$ in our cohort and in $25 \%$ of all patients who died in the first year following surgery. All cases of surgical mortality were caused only by specific surgical complications - POPF and PPH. Our surgical mortality rate is comparable to data presented by Petrova et al. ${ }^{36}$ and Byrling et al. ${ }^{52}$, where in-hospital mortality was $7.9 \%$ and $8.0 \%$, respectively. On the other hand, when compared to our previously published study of PDAC patients ${ }^{53}$, the mortality rate of PD in DCC patients seems significantly higher than in PDAC patients $-9.4 \%$ vs. $3.3 \%$. This is probably due to obstruction and chronic inflammatory and fibrous parenchymal changes within the pancreatic tissue among PDAC patients. Contrarily, there is no obstruction nor parenchymal fibrotisation in the pancreas in DCC patients, and anastomotic complications are more frequent.

Because our study is retrospective with a limited number of patients, in addition to the fact that most of the previously published DCC analyses studied the prognostic DCC factors, large pooled data or a large multicentric trial should be used to assess the significance of surgical-related factors and their prognostic impact on DCC prognosis.

\section{CONCLUSION}

The prognosis of patients with DCC is dismal. The main factor directly influencing the survival of DCC patients is surgical complications. Surgical mortality comprises a significant group of patients, who die in the first year following PD. Vascular resection is the most important negative prognostic factor for long-term survival.

\section{ABBREVIATIONS}

ASA, American Society of Anesthesiologists; CA 19-9, Carbohydrate antigen 19-9; CD, Clavien-Dindo classification; CI, Confidence interval; DCC, Distal cholangiocarcinoma; DGE, Delayed gastric emptying; ERCP, Endoscopic retrograde cholangiopancreatography; HRs, Hazard ratios; ICU, Intensive care unit;
ISGPS, International Study Group of Pancreatic Surgery; LNR, Lymph node ratio; OS, Overall Survival; PD, Pancreaticoduodenectomy; PDAC, Pancreatic ductal adenocarcinoma; POPF, Postoperative pancreatic fistula; PPH, Postoperative pancreatic haemorrhage; PTC, Percutaneous transhepatic cholangiography.

Acknowledgements: This research was funded by the Ministry of Health of the Czech Republic NV 19-0900088 to ML and DRO FNOL 00098892 (MEX 87-94) to ML.

Author contributions: PS, ML: manuscript writing and conducting the literature review; OU, DK: provided broad ideas and structure, as well as revisions; PS, ML, JE, HS, JT, KK: concept and design, data collection and review; PS, ML: manuscript draft; $\mathrm{CN}$ : critical revision of the manuscript and final approval of the manuscript.

Conflict of interest statement: The authors state that there are no conflicts of interest regarding the publication of this article.

\section{REFERENCES}

1. Beetz O, Klein M, Schrem H, Gwiasda J, Vondran FWR, Oldhafer F, Camman S, Klempnauer J, Oldhafer KJ, Kleine M. Relevant prognostic factors influencing outcome of patients after surgical resection of distal cholangiocarcinoma. BMC Surgery 2018;18:56.

2. Zhou Y, Liu S, Wu L, Wan T. Survival after surgical resection of distal cholanguiocarcinoma: A systematic review and meta-analysis of prognostic factors. Asian J Surg 2017;40:129-38.

3. Li X, Lin H, Sun Y, Gong J, Feng H, Tu J. Prognostic significance of the lymph node ratio in surgical patients with distal cholangiocarcinoma. J Surg Res 2019;236:2-11.

4. Dusek L, Muzik J, Kubasek M, Koptikova J, Zaloudik J, Vyzula R. Epidemiologie zhoubných nádorů v České republice [online]. Masarykova univerzita. 2005 [cited 2021 Jan 17]. Available from: http://www.svod.cz (In Czech)

5. Kamsa-Ard S, Luvira V, Suwanrungruang K, Kamsa-Ard S, Luvira V, Santong C, Srisuk T, Pugkhem A, Bhudhisawasdi V, Pairojkul CJ. Cholangiocarcinoma Trends, Incidence, and Relative Survival in Khon Kaen, Thailand From 1989 Through 2013: A Population-Based Cancer Registry Study. Epidemiol 2019;29(5):197-204.

6. Murakami Y, Uemura K, Sudo T, Hashimoto Y, Nakashima A, Kondo N Sakabe R, Ohge H, Sueda T. Prognostic factors after surgical resection for intrahepatic, hilar, and distal cholangiocarcinoma. Ann Surg Oncol 2011;18(3):651-8.

7. Kim BH, Kim K, Chie EK, Kwon J, Jang JY, Kim SW, Oh DY, Bang YJ. Long-Term Outcome of Distal Cholangiocarcinoma after Pancreaticoduodenectomy Followed by Adjuvant Chemoradiotherapy: A 15-Year Experience in a Single Institution. Cancer Res Treat 2017;49(2):473-83.

8. DeOliveira ML, Cunningham SC, Cameron JL, Kamangar F, Winter JM, Lillemoe KD et al. Cholangiocarcinoma: thirty-one-year experience with 564 patients at a single institution. Ann Surg 1999;229:76-83.

9. Ito K, Sakamoto Y, Isayama H, Nakai Y, Watadani T, Tanaka M, Ushiku T, Akamatsu N, Kaneko J, Arita J, Hasegawa K, Kokudos N. The Impact of MDCT and Endoscopic Transpapillary Mapping Biopsy to Predict Longitudinal Spread of Extrahepatic Cholangiocarcinoma. J Gastrointest Surg 2018;22(9):1528-37.

10. Jang JY, Kim SW, Park DJ, Ahn YJ, Yoon YS, Choi MG, Suh KS, Lee KU, Park YH. Actual long-term outcome of extrahepatic bile duct cancer after surgical resection. Ann Surg 2005;241:77-84.

11. Bahra M, Jacob D, Langrehr JM, Neumann UP, Neuhaus P. Carcinoma of the distal and middle bile duct: surgical results, prognostic factors, and long-term follow-up. J Hepato-Biliary-Pancreat Surg 2008;15:501-7.

12. Dindo D, Demartines N, Clavien PA. Classification of surgical compli- 
cations: A new proposal with evaluation in a cohort of 6336 patients and results of a survey. Ann Surg 2004;240:205-13.

13. Wente MN, Bassi C, Dervenis C, Fingerhut A, Gouma DJ, Izbicki JR, Neoptolemos JP, Padbury RT, Sarr MG, Traverso LW, Yeo CJ, Büchler MW. Delayed gastric emptying (DGE) after pancreatic surgery: A suggested definition by the International Study Group of Pancreatic Surgery (ISGPS). Surgery 2007;142:761-8.

14. Wente MN, Veit JA, Bassi C, Dervenis C, Fingerhut A, Gouma DJ, Izbicki JR, Neoptolemos JP, Padbury RT, Sarr MG, Yeo CJ, Büchler MW. Postpancreatectomy hemorrhage (PPH): An International Study Group of Pancreatic Surgery (ISGPS) definition. Surgery 2007;142:20-5.

15. Bassi C, Marchegiani G, Dervenis C, Sarr M, Abu Hilal M, Adham M, Allen P, Andersson R, Asbun HJ, Besselink MG, Conlon K, Del Chiaro $M$, Falconi M, Fernandez-Cruz L, Fernandez-Del Castillo C, Fingerhut A, Friess H, Gouma DJ, Hackert T, Izbicki J, Lillemoe KD, Neoptolemos JP, Olah A, Schulick R, Shrikhande SV, Takada T, Takaori K, Traverso W, Vollmer CR, Wolfgang CL, Yeo CJ, Salvia R, Buchler M; International Study Group on Pancreatic Surgery (ISGPS). The 2016 update of the International Study Group (ISGPS) definition and grading of postoperative pancreatic fistula: 11 Years After. Surgery 2017;161:584-91.

16. Tol JA, Gouma DJ, Bassi C, Dervenis C, Montorsi M, Adham M, Andren-Sandberg A, Asbun HJ, Bockhorn M, Buchler MW, Conclon KC, Fernandes-Cruz L, Fingerhut A, Friess H, Hartwig W, Izbicki JR, Lillemoe KD, Milicevic MN, Neoptolemos JP, Shrikhande SV, Vollmer CM, Yeo CJ, Charnley RM, International Study Group on Pancreatic Surgery. Definition of a standard lymphadenectomy in surgery for pancreatic ductal adenocarcinoma: a consensus statement by the International Study Group on Pancreatic Surgery (ISGPS). Surgery 2014;156(3):591-600.

17. Chung YJ, Choi DW, Choi SH, Heo JS, Kim DH. Prognostic factors following surgical resection of distal bile duct cancer. J Korean Surg Soc 2013;85:212-18.

18. Kiriyama M, Ebata T, Aoba T, Kaneoka Y, Arai T, Shimizu Y, Nagino M; Nagoya Surgical Oncology Group. Prognostic impact of lymph node metastasis in distal cholangiocarcinoma. Br J Surg 2015;102:399-406.

19. Ishihara S, Horiguchi A, Miyakawa S, Endo I, Miyazaki M, Takada T. Biliary tract cancer registry in Japan from 2008 to 2013. J Hepatobiliary Pancreat Sci 2016;23:149-57.

20. Courtin-Tanguy L, Rayar M, Bergeat D, Merdrignac A, Harnoy $Y$ Boudjema K, Meunier B, Sulpice L. The true prognosis of resected distal cholangiocarcinoma. J Surg Oncol 2016;113:575-80.

21. Tol JA, Brosens LA, van Dieren S, van Gulik TM, Busch OR, Besselink MG, Gouma DJ. Impact of lymph node ratio on survival in patients with pancreatic and periampullary cancer. Br J Surg 2015;102:23745.

22. Ercolani G, Dazzi A, Giovinazzo F, Ruzzenente A, Bassi C, Guglielm A, Scarpa A, D'Errico A, Pinna AD. Intrahepatic, peri-hilar and distal cholangiocarcinoma: Three different locations of the same tumor or three different tumors? Eur J Surg Oncol 2015;41:1162-9.

23. Andrianello S, Paiella S, Allegrini V,Ramera M, Pulvirenti A, Malleo G, Salvia R, Bassi C. Pancreaticoduodenectomy for distal cholangiocarcinoma: Surgical results, prognostic factors, and long-term followup. Langenbecks Arch Surg 2015;400:623-8.

24. Gaag NA, Kloek JJ, de Bakker JK, Musters B, Geskus RB, Busch OR, Bosma A, Gouma DJ, van Gulik TM. Survival analysis and prognostic nomogram for patients undergoing resection of extrahepatic cholangiocarcinoma. Ann Oncol 2012;23:264-9.

25. Ebata T, Nagino $M$, Nishio $H$, Igami T, Yokoyama $Y$, Nimura $Y$. Pancreatic and duodenal invasion in distal bile duct cancer: paradox in the tumor classification of the American joint committee on Cancer. World J Surg 2007;31:2008-15.

26. Nakeeb A, Pitt HA, Sohn TA, Coleman J, Abrams RA, Piantadosi $S$, Hruban RH, Lillemoe KD, Yeo CJ, Cameron JL. Cholangiocarcinoma. A spectrum of intrahepatic, perihilar, and distal tumors. Ann Surg 1996:224:463-73.

27. Choi SB, Park SW, Kim KS, Choi JS, Lee WJ. The survival outcome and prognostic factors for middle and distal bile duct cancer following surgical resection. J Surg Oncol 2009;99:335-42.

28. Hong SM, Pawlik TM, Cho H, Aggarwal B, Goggins M, Hruban RH, Anders RA. Depth of tumor invasion better predicts prognosis than the current American Joint Committee on Cancer T classification for distal bile duct carcinoma. Surgery 2009;146:250-7.

29. Hernandez J, Cowgill SM, Al-Saadi S, Villadolid D, Ross S, Kraemer E, Shapiro M, Mullinax J, Cooper J, Goldin S, Zervos E, Rosemurgy A. An Aggressive Approach To Extrahepatic Cholangiocarcinomas Is
Warranted: Margin Status Does Not Impact Survival After Resection. Ann Surg Oncol 2008;15:807-14.

30. Yoshida T, Matsumoto T, Sasaki A, Morii Y, Aramaki M, Kitano S. Prognostic factors after pancreatoduodenectomy with extended lymphadenectomy for distal bile duct cancer. Arch Surg 2002;137:6973.

31. Bortolasi L, Burgart LJ, Tsiotos GG, Luque-De León E, Sarr MG. Adenocarcinoma of the distal bile duct. A clinicopathologic outcome analysis after curative resection. Dig Surg 2000;17:36-41.

32. Kim HJ, Kim CY, Hur YH, Koh YS, Kim JC, Kim HJ, Cho CK. Prognostic factors for survival after curative resection of DCC: perineural invasion and lymphovascular invasion. Surg Today 2014;44:1879-86.

33. Yoshida T, Matsumoto T, Sasaki A, Morii Y, Aramaki M, Kitano S. Prognostic factors after pancreatoduodenectomy with extended lymphadenectomy for distal bile duct cancer. Arch Surg 2002;137:6973.

34. Hernandez J, Cowgill SM, Al-Saadi S, Villadolid D, Ross S, Kraemer E, Shapiro M, Mullinax J, Cooper J, Goldin S, Zervos E, Rosemurgy A. An aggressive approach to extrahepatic cholangiocarcinomas is warranted: margin status does not impact survival after resection. Ann Surg Oncol 2008;15:807-14.

35. Wellner UF, Shen Y, Keck T, Jin W, Xu Z. The survival outcome and prognostic factors for distal cholangiocarcinoma following surgical resection: a meta-analysis for the 5-year survival. Surg Today 2017:47:271-9.

36. Petrova E, Ruckert F, Zach S, Shen Y, Weitz J, Grützmann R, Wittel UA, Makowiec F, Hopt UT, Bronsert P, Kühn F, Rau BM, Izrailov RE, Khatkov IE, Lapshyn H, Bolm L, Bausch D, Keck T, Wellner UF, Seifert G. Survival outcome and prognostic factors after pancreatoduodenectomy for distal bile duct carcinoma: a retrospective multicenter study. Langenbeck's Arch Surg 2017;402:831-40.

37. Urban O, Evinová $E$, Fojtík $P$, Loveček $M$, Kliment $M$, Zoundjiekpon V, Falt P. Digital cholangioscopy: the diagnostic yield and impact on management of patients with biliary stricture. Scand J Gastroenterol 2018;53(10-11):1364-7.

38. Shiraki T, Kuroda H, Takada A, Nakazato Y, Kubota K, Imai Y Intraoperative frozen section diagnosis of bile duct margin for extrahepatic cholangiocarcinoma. World J Gastroenterol 2018;24(12):1332-42

39. Hajer J, Havlůj L, Whitley A, Oliverius M, Gürlich R. The role of singleoperator cholangioscopy (SpyGlass) in the intraoperative diagnosis of intraductal borders of cholangiocarcinoma proliferation - pilot study. Cas Lek Cesk 2019;158(2):68-72. (In Czech)

40. Hong SM, Cho H, Lee OJ, Ro JY. The number of metastatic lymph nodes in extrahepatic bile duct carcinoma as a prognostic factor. Am J Surg Pathol 2005;29:1177-183.

41. Murakami Y, Uemura K, Hayashidani Y, Sudo T, Hashimoto Y, Ohge $\mathrm{H}$, Sueda T. Prognostic significance of lymph node metastasis and surgical margin status for distal cholangiocarcinoma. J Surg Oncol 2007;95:207-12.

42. Murakami $Y$, Uemura $K$, Hayashidani $Y$, Sudo T, Ohge $H$, Sueda $T$. Pancreatoduodenectomy for distal cholangiocarcinoma: Prognostic impact of lymph node metastasis. World J Surg 2007;31:337-42.

43. Pomianowska E, Westgaard A, Mathisen O, Clausen OP, Gladhaug IP. Prognostic relevance of number and ratio of metastatic lymph nodes in resected pancreatic, ampullary, and distal bile duct carcinomas. Ann Surg Oncol 2013;20:233-41.

44. Yamashita K, Hosoda K, Ema A, Watanabe M. Lymph node ratio as a novel and simple prognostic factor in advanced gastric cancer. Eur J Surg Oncol 2016;42(9):1253-60.

45. Ozawa T, Ishihara S, Nishikawa T, Tanaka T, Tanaka J, Kiyomatsu T, Hata K, Kawai K, Nozawa H, Kanazawa T, Kazama S, Yamaguchi H, Sunami E, Kitayama J, Watanabe T. Prognostic significance of the lymph node ratio in stage IV colorectal cancer patients who have undergone curative resection. Ann Surg Oncol 2015;22:1513-9.

46. Zhang MR, Xie TH, Chi JL, Li Y, Yang L, Yu YY, Sun XF, Zhou ZG. Prognostic role of the lymph node ratio in node positive colorectal cancer: a meta-analysis. Oncotarget 2016;7(45):72898-907.

47. Fischer LK, Katz MH, Lee SM, Liu L, Wang H, Varadhachary GR, Wolff RA, Lee JE, Maitra A, Roland CL, Fleming JB, Estrella J, Rashid A. The number and ratio of positive lymph nodes affect pancreatic cancer patient survival after neoadjuvant therapy and pancreaticoduodenectomy. Histopathology 2016;68(2):210-20.

48. Kawai M, Tani M, Kobayashi Y, Kobayashi Y, Tsuji T, Tabuse K, Horiuchi T, Oka M, Yamaguchi K, Sakata Y, Shimomura T, Yamaue H. The ratio 
between metastatic and examined lymph nodes is an independent prognostic factor for patients with resectable middle and distal bile duct carcinoma. Am J Surg 2010;199:447-52

49. Oshiro Y, Sasaki R, Kobayashi A, Murata S, Fukunaga K, Kondo T, Oda T, Ohkohchi N. Prognostic relevance of the lymph node ratio in surgical patients with extrahepatic cholangiocarcinoma. Eur J Surg Oncol 2011;37:60-4.

50. Miura F, Sano K, Amano H, Toyota N, Wada K, Yoshida M, Hayano $\mathrm{K}$, Matsubara $\mathrm{H}$, Takada T. Evaluation of portal vein invasion of distal cholangiocarcinoma as borderline resectability. J Hepatobiliary Pancreat Sci 2015;22:294-300.

51. Maeta T, Ebata T, Hayashi E, Kawahara T, Mizuno S, Matsumoto
N, Ohta S, Nagino M; Nagoya Surgical Oncology Group. Pancreatoduodenectomy with portal vein resection for distal cholangiocarcinoma. Br J Surg 2017;104:1549-57.

52. Byrling J, Andersson R, Sasor A, Lindell G, Ansari D, Nilsson J, Andersson B. Outcome and evaluation of prognostic factors after pancreaticoduodenectomy for distal cholangiocarcinoma. Ann of Gastroenterology 2017;30:571-7.

53. Lovecek M, Skalicky P, Klos D, Bebarova L, Neoral C, Ehrmann J, Zapletalova J, Svebisova H, Vrba R, Stasek M, Yogeswara T, Havlik R. Long-term survival after resections for pancreatic ductal adenocarcinoma. Single centre study. Biomed Pap Med Fac Univ Palacky Olomouc Czech Repub. 2016; 160(2):280-6. 